\title{
INFLUENCE OF SIDEROPHORES AND IRON ON MYCOBACTERIUM BOVIS ISOLATION FROM PATHOLOGICAL MATERIAL
}

\author{
Zavgorodniy A. I., Pozmogova S. A., Bilushko V. V., Kalashnyk M. V., Gologurska O. I. \\ National Scientific Center 'Institute of Experimental and Clinical \\ Veterinary Medicine’, Kharkiv, Ukraine, e-mail: nick.v.kalashnik@gmail.com
}

\begin{abstract}
Summary. The article presents the results of studying the effect of siderophores and iron on the isolation of Mycobacterium bovis from pathological material. It has been established that the simultaneous presence of iron and siderophore from $M$. phlei in the nutrient medium makes it possible to detect the growth of $M$. bovis from pathological material 6-8 days earlier; ensures the growth of more colonies and bacterial mass. The presence of heterologous to mycobacteria siderophore (from Nocardia spp.) in the medium reduces the elective (growth) properties of the medium. Siderophores found in the culture filtrate or alcoholic extract of $M$. phlei can be valuable additives to culture media for the accelerated isolation of $M$. bovis from pathological material
\end{abstract}

Keywords: Mycobacterium phlei, Nocardia asteroides, nutrient media, elective properties

Introduction. Laboratory diagnostics based on the direct isolation of the pathogen from biological material is one of the priority areas in tuberculosis control. Despite the existence of methods for tuberculosis diagnosing, the culture method retains its significance and is the 'gold' standard for isolating and studying the pathogen. However, in vitro cultivation of mycobacteria significantly loses its diagnostic value due to the long periods of generation of the mycobacterium tuberculosis complex. This is due to the peculiarities of the metabolism of mycobacteria and the complex structure of the cell wall, which is relatively impermeable for the exchange of metabolites between the bacterium and its host during chronic intracellular infection (Lyamin et al., 2016; Dobin, Demikhov and Zharikova, 2016).

For successful reproduction in the host organism, pathogens need iron, which takes part in the basic metabolic processes of mycobacteria, including respiration, the Krebs cycle, oxygen transport, gene regulation, protection against oxidative stress, and DNA biosynthesis (Rodriguez, 2006; Arnold et al., 2020; Andrews, Robinson and Rodríguez-Quiñones, 2003).

However, in the tissues of the macroorganism, the concentration of this metal is very low, since iron $\mathrm{Fe}^{+3}$ is sequestered by iron-binding proteins such as transferrin, lactoferrin, ferritin, hemopexin, and haptoglobin (Hood and Skaar, 2012; Takatsuka et al., 2011; Dobryszycka, 1997; Tolosano and Altruda, 2002; Jones and Niederweis, 2011; Tullius et al., 2011; Drakesmith and Prentice, 2012).

Mycobacteria have developed both general and specialized systems to transport iron molecules through cell walls (DiGiuseppe Champion and Cox, 2007; Agoro and Mura, 2019).

Iron production mechanisms include: synthesis of siderophores together with siderophore-based transport systems; the acquisition of metal directly from the host's iron-binding proteins (transferrin and lactoferrin); absorption and utilization of heme; dissolution of iron oxides by reduction of iron oxide and transport of soluble forms (Tanner et al., 2017).
Mycobacteria synthesize three types of siderophores to bind and transport iron - mycobactin, carboxymycobactin, and exochelin. The mycobactin molecule is associated with the cell wall of mycobacteria and provides the transfer of iron into the cell, while carboxymycobactin and exochelin are secretory molecules. Saprophytic mycobacteria, living in the soil, synthesize and secrete mainly exochelin, while pathogenic mycobacteria - carboxymycobactin (Fang et al., 2015).

Mutants with impaired mycobactin biosynthesis lose the ability to replicate in vivo and in vitro (Reddy et al., 2013; Rodriguez and Smith, 2006; Knobloch et al., 2020). In addition to mycobacteria, siderophores are also synthesized by closely related to mycobacteria Nocardia spp. (nocabactin) (Hoshino et al., 2011; Dhakal et al., 2019; Männle et al., 2020).

When conditions change from in vivo to in vitro, mycobacterium tuberculosis temporarily loses the ability to independently synthesize some substances necessary for generation and growth in vitro. Therefore, additional time is required for M. bovis to adapt to other conditions, different from laboratory-adapted strains. Rich in a variety of bioavailable organic and inorganic nutrients nutrient media are required for the generation and growth of pathogenic mycobacteria.

The research aimed to study the effect of siderophores and iron on the isolation of the tuberculosis pathogen from biological material and to determine the effectiveness of culture media with different growth factors in the isolation and cultivation of M. bovis.

Materials and methods. The research used reference cultures of M. bovis strain Vallee and M. phlei, which are stored in the mycobacteria collection of the laboratory for the study of tuberculosis of the National Scientific Center 'Institute of Experimental and Clinical Veterinary Medicine' (Kharkiv, Ukraine).

A field isolate of Nocardia asteroides was isolated from cattle lymph nodes.

The research was carried out using biological and cultural methods. 
Infection of laboratory animals. Guinea pigs $(\mathrm{n}=3)$ were infected with a suspension of M. bovis, strain Vallee, at a dose of $1.0 \mathrm{mg}$ of bacterial mass in $1.0 \mathrm{~cm}^{3}$ of sterile isotonic $\mathrm{NaCl}$ solution. After 30 days, the guinea pigs were euthanized, and the liver and spleen were collected for cultural research.

Pre-plating treatment and plating of pathological material. The biomaterial (liver, spleen) was rubbed with sterile sand, and $0.85 \% \mathrm{NaCl}$ solution was added to the homogenate in a ratio of 1:3. After precipitation of sand and large particles, the supernatant was collected and centrifuged. The precipitate was decontaminated with $6 \%$ sulfuric acid for $20 \mathrm{~min}$ and then washed by centrifugation in $0.85 \% \mathrm{NaCl}$ solution. The sediment of the biological material was resuspended in a small amount of $0.85 \% \mathrm{NaCl}$ and seeded $0.3 \mathrm{~cm}^{3}$ on each nutrient medium $(n=5)$. The cultures were cultivated at a temperature of $37.5 \pm 0.5^{\circ} \mathrm{C}$ for one month.

The rate of appearance of the first colonies, the intensity of growth (the number and size of colonies), and the amount of bacterial mass served as indicators of the effect of various additives on the M. bovis growing.

Preparation of culture media. Based on the 'Dry nutrient medium for the cultivation of mycobacteria' we prepared five versions of egg media with various additives. Medium I contained $25 \%$ of the culture filtrate of the liquid medium, on which $M$. phlei and ammonium citrate iron were cultivated at a concentration of $0.0075 \mathrm{~g}$ per $100.0 \mathrm{~cm}^{3}$, medium II $-2 \%$ ethanol extract of dry bacterial mass $N$. asteroides and citric ammonium iron at a concentration of $0.0075 \mathrm{~g}$ per $100.0 \mathrm{~cm}^{3}$, medium III $2 \%$ ethanol extract of dry bacterial mass of $M$. phlei and citric-ammonium iron at a concentration of $0.0075 \mathrm{~g}$ per $100.0 \mathrm{~cm}^{3}$, medium IV $-2 \%$ ethanol extract of dry bacterial mass M.phlei (without ammoniacal iron), medium $\mathrm{V}$ - control (without siderophores and iron). All additives were added just before the coagulation of the medium.

Preparation of M. phlei culture filtrate and ethanol extracts of M.phlei and N. asteroides. The culture of M. phlei and N. asteroides was cultivated for 4 weeks in bottles with a liquid medium containing asparagine, potassium phosphate, sodium phosphate, sodium citrate, magnesium sulfate, ammonium ferrous sulfate, and glucose. Culture was inactivated by autoclaving at $132^{\circ} \mathrm{C}$ for $60 \mathrm{~min}$. The bacterial mass of M. phlei and $N$. asteroides was separated from the liquid part of the medium by filtration through a double paper filter. The culture filtrate of $M$. phlei was sterilized. The bacterial mass of M. phlei and N. asteroides was dried, ground into powder, and extracted in ethanol in an oven at $90^{\circ} \mathrm{C}$.

Statistical analysis was performed by counting colonies, determining the arithmetic mean and standard error $(\mathrm{M} \pm \mathrm{m})$.

Results and discussion. The autopsy of guinea pigs 30 days after infection with a suspension of M. bovis strain Vallee revealed enlarged inguinal lymph nodes and characteristic tuberculous lesions in the form of single grayish-white small nodules in the spleen and liver, which indicated the pathogenicity of the strain. From the results of the culture study, we found that the addition of various siderophores and ammonium-lemon iron to the nutrient medium has a positive effect on the rate and intensity of growth (Figs. 1-4).

The results of a comparative study of the effectiveness of nutrient media in the isolation of mycobacteria from biomaterial are presented in Table 1.

As can be seen from the data in Table 1, when isolating M.bovis, the Vallee strain from biological material from infected guinea pigs, the nutrient medium I with the addition of M. phlei culture filtrate and citric ammonium iron had the best growth qualities, namely, in terms of the rate of appearance of visible colonies and their number.

So, on the surface of the bevels of this medium, the visible growth of the first single colonies less than $0.5 \mathrm{~mm}$ in size was noted in 2 tubes on the $7^{\text {th }}$ day of cultivation, the growth in all tubes was detected on the $11^{\text {th }}$ day of incubation.

The research results indicate that the growth rate of the primary colonies of the nutrient medium I is superior to the rest of the mediums.

On medium I, compared with the rest of the studied media, the growth of the causative agent of tuberculosis (in all test tubes) was noted seven days earlier. On media with iron and ethanol extracts of M.phlei (III) and $N$. asteroides (II), on $15^{\text {th }}$ day, in 3 tubes of each medium, single colonies (less than $0.5 \mathrm{~mm}$ ) were detected although on medium III in one test tube on $11^{\text {th }}$ day, the growth of one colony was noted. Regarding medium IV, which included only $M$. phlei extract (without iron) and control medium $\mathrm{V}$, the growth of 1-2 colonies was observed in one tube of each medium on $15^{\text {th }}$ day. We noted the presence of colonies on media II, III, IV, V in all test tubes at the same time - on $18^{\text {th }}$ day.

Differences were also in terms of the intensity of growth of colonies (number, size, amount of bacterial mass). After 30 days of cultivation, the average number of colonies $(\mathrm{M} \pm \mathrm{m})$ on medium I was $90.0 \pm 6.8$, which is 2.1 times more than the number of colonies on control medium V $(43.2 \pm 3.4)$. The average number of colonies on medium III was $78.2 \pm 4.6$, then medium II with $65.8 \pm 5.2$ and medium IV with $52.8 \pm 4.4$ colonies, which, respectively, $1.8,1.5$ and 1.2 times more than the number of colonies on the control medium.

In addition, as can be seen from Table 1, the amount of bacterial mass on the medium I with the culture filtrate M. phlei and iron, compared with the rest of the media, was also greater and amounted to $60.0 \pm 3.5 \mathrm{mg}$, which is 1.6, 1.2, 1.27, 1.33 times more than 'raw' weight of the bacterial mass from medium II $(37.5 \pm 2.7 \mathrm{mg})$, medium III $(49.3 \pm 3.1 \mathrm{mg})$, medium IV $(47.0 \pm 3.6 \mathrm{mg})$ and control medium $(45.0 \pm 3.4 \mathrm{mg})$, respectively. It is important to note that on the control medium $\mathrm{V}$, despite the smaller number of colonies $(43.2 \pm 3.4)$, their size after 30 days of cultivation was significantly larger than on all other media, which affected the weight of the bacterial mass ( $45.0 \pm 3.4 \mathrm{mg}$ ). 


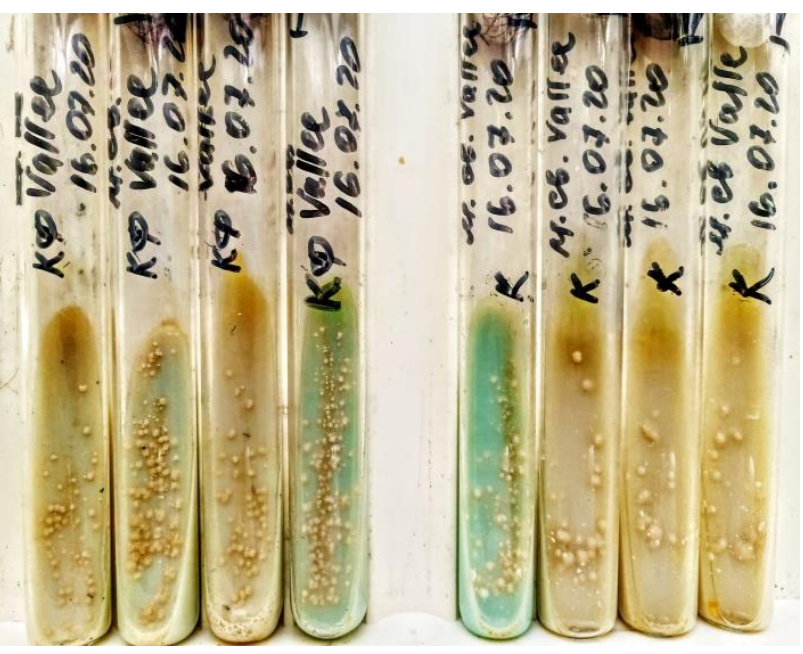

Figure 1. Growth of strain Vallee on media I and V (control)

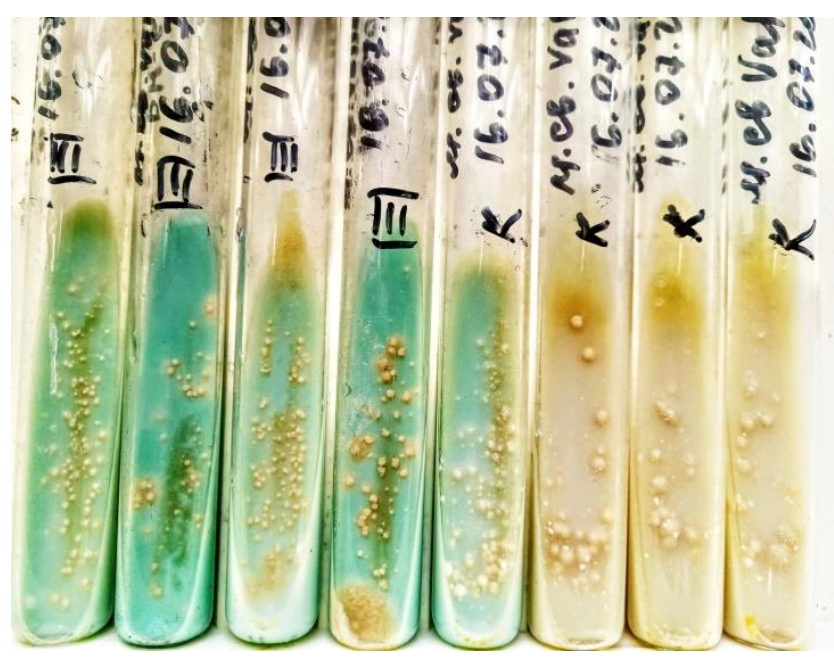

Figure 3. Growth of strain Vallee on media III and V (control)

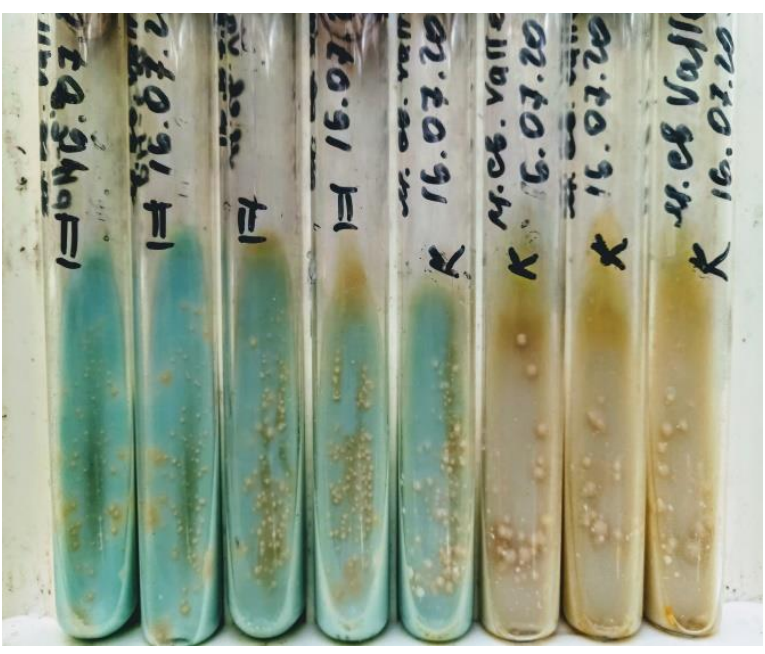

Figure 2. Growth of strain Vallee on media II and V (control)

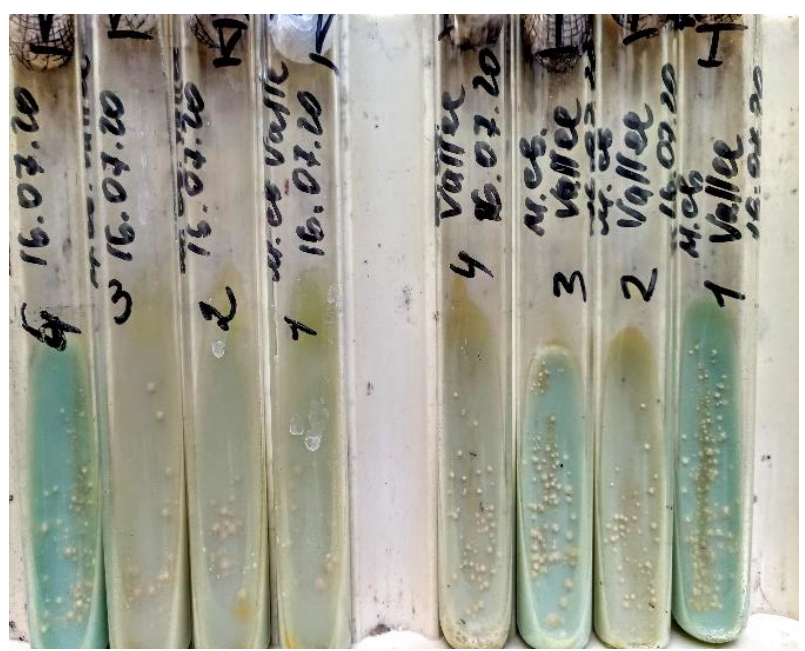

Figure 4. Growth of strain Vallee on media IV and V (control)

Table 1 - Results of studying the effect of siderophores and iron in isolating M. bovis strain Vallee from biological material

\begin{tabular}{|c|c|c|c|c|c|c|c|c|c|c|}
\hline \multirow{3}{*}{ Medium } & \multirow{3}{*}{$\begin{array}{l}\text { No. of the } \\
\text { test tube }\end{array}$} & \multicolumn{7}{|c|}{ Days of cultivation } & \multirow{3}{*}{$\begin{array}{c}\text { Number } \\
\text { of colonies, } \\
\mathbf{M} \pm \mathbf{m}\end{array}$} & \multirow{3}{*}{$\begin{array}{c}\text { Bacterial mass } \\
\text { weight, mg/test } \\
\text { tube, } M \pm \text { m }\end{array}$} \\
\hline & & 7 & 11 & 15 & 18 & 20 & 25 & 30 & & \\
\hline & & \multicolumn{7}{|c|}{ Number of colonies } & & \\
\hline \multirow{5}{*}{$\begin{array}{c}\mathrm{I} \\
(\mathrm{CF}+\mathrm{Fe})\end{array}$} & 1 & 1 & 3 & 10 & 16 & 36 & 72 & 102 & \multirow{5}{*}{$90.0 \pm 4.6$} & \multirow{5}{*}{$60.0 \pm 3.5$} \\
\hline & 2 & - & 1 & 5 & 12 & 22 & 48 & 79 & & \\
\hline & 3 & - & 2 & 7 & 14 & 29 & 52 & 84 & & \\
\hline & 4 & - & 1 & 4 & 10 & 19 & 46 & 86 & & \\
\hline & 5 & 2 & 4 & 6 & 13 & 22 & 68 & 99 & & \\
\hline \multirow{5}{*}{$\begin{array}{c}\mathrm{II} \\
(\mathrm{ExNoc}+\mathrm{Fe})\end{array}$} & 1 & - & - & 4 & 6 & 16 & 38 & 74 & \multirow{5}{*}{$65.8 \pm 5.2$} & \multirow{5}{*}{$37.5 \pm 2.7$} \\
\hline & 2 & - & - & - & 3 & 8 & 46 & 80 & & \\
\hline & 3 & $\begin{array}{llll}- & & & \end{array}$ & $\begin{array}{lll}- & & \\
\end{array}$ & 3 & 7 & 13 & 25 & 55 & & \\
\hline & 4 & - & - & 2 & 8 & 12 & 27 & 54 & & \\
\hline & 5 & - & - & - & 4 & 9 & 33 & 66 & & \\
\hline \multirow{5}{*}{$\begin{array}{c}\text { III } \\
(\mathrm{ExPhl}+\mathrm{Fe})\end{array}$} & 1 & - & - & - & 3 & 11 & 42 & 95 & \multirow{5}{*}{$78.2 \pm 4.6$} & \multirow{5}{*}{$49.3 \pm 3.1$} \\
\hline & 2 & - & - & 2 & 6 & 14 & 33 & 74 & & \\
\hline & 3 & - & 1 & 3 & 6 & 12 & 38 & 69 & & \\
\hline & 4 & - & - & 1 & 5 & 13 & 39 & 71 & & \\
\hline & 5 & - & - & - & 4 & 10 & 33 & 82 & & \\
\hline
\end{tabular}


Continuation of Table 1

\begin{tabular}{|c|c|c|c|c|c|c|c|c|c|c|}
\hline \multirow{3}{*}{ Medium } & \multirow{3}{*}{$\begin{array}{l}\text { No. of the } \\
\text { test tube }\end{array}$} & \multicolumn{7}{|c|}{ Days of cultivation } & \multirow{3}{*}{$\begin{array}{c}\text { Number } \\
\text { of colonies, } \\
\mathbf{M} \pm \mathbf{m}\end{array}$} & \multirow{3}{*}{$\begin{array}{c}\text { Bacterial mass } \\
\text { weight, } \mathrm{mg} / \text { test } \\
\text { tube, } M \pm \mathrm{m}\end{array}$} \\
\hline & & 7 & 11 & 15 & 18 & 20 & 25 & 30 & & \\
\hline & & \multicolumn{7}{|c|}{ Number of colonies } & & \\
\hline \multirow{5}{*}{$\begin{array}{c}\text { IV } \\
\text { (ExPhl) }\end{array}$} & 1 & - & - & - & 4 & 7 & 24 & 48 & \multirow{5}{*}{$52.8 \pm 4.4$} & \multirow{5}{*}{$47.0 \pm 3.6$} \\
\hline & 2 & - & - & - & 3 & 8 & 27 & 40 & & \\
\hline & 3 & - & - & 2 & 10 & 21 & 41 & 62 & & \\
\hline & 4 & - & - & - & 6 & 11 & 36 & 59 & & \\
\hline & 5 & - & - & - & 5 & 9 & 31 & 55 & & \\
\hline \multirow{5}{*}{$\begin{array}{c}\mathrm{V} \\
\text { (control) }\end{array}$} & 1 & - & - & - & 3 & 8 & 26 & 42 & \multirow{5}{*}{$43.2 \pm 3.4$} & \multirow{5}{*}{$45.0 \pm 3.4$} \\
\hline & 2 & - & - & - & 6 & 16 & 28 & 43 & & \\
\hline & 3 & - & - & 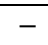 & 4 & 12 & 21 & 34 & & \\
\hline & 4 & - & - & 1 & 12 & 35 & 35 & 45 & & \\
\hline & 5 & - & - & - & 6 & 12 & 43 & 52 & & \\
\hline
\end{tabular}

Notes: CF - culture filtrate M. phlei; ExNoc - ethanol extract N. asteroides; ExPhl - ethanol extract M. phlei; $\mathrm{Fe}-$ citric ammonium iron.

The ratio of the number of colonies to the weight of the bacterial mass on medium $\mathrm{V}$ was less than one, while on medium I, this figure was 1.5 , on medium II -1.7 , on medium III -1.6 , on medium IV - 1.1 .

Thus, from the results of a comparative study of the effectiveness of culture media, it follows that the inclusion of a homologous (mycobacterial) siderophore and iron in the composition makes it possible to improve the quality of the culture medium, and, on the contrary, the addition of heterologous nocabactin does not stimulate the growth of the bacterial mass of M. bovis. These data are consistent with studies by other authors.

It was reported that a phytosiderophore extracted from plant roots inhibits the growth of the Mtb H37Ra strain in vitro (Rajiv et al., 2001). According to Gokarn and Pal (2017), M. smegmatis exocholine at a dose of $0.5 \mathrm{mg} / \mathrm{ml}$ selectively inhibited the growth of M. tuberculosis. An important observation was that the inhibitory activity of siderophores was canceled when iron was added to the medium. This proves the bacteriostatic effect of heterologous siderophores, which is solely due to their ability to deprive pathogens of iron (Gokarn and Pal, 2017; He and Xie, 2011).

This is since the fact that the $\mathrm{Fe}^{3+}$ ion forms a complex with a heterologous relative to Mycobacterium siderophore (in this case, nocabactin); the absence of specific receptors in mycobacteria will affect the absorption of iron and reduce its availability, which ultimately affects the growth of the pathogen. This statement is confirmed by the data in Table 1 , on a medium with an extract of N.asteroides and iron (medium II), the weight of the bacterial mass was the smallest.

The source of iron for mycobacteria in the macroorganism is the host metalloproteins (transferrin, ferritin, lactoferrin, hemproteins, primarily hemoglobin, as well as heme-containing enzymes) (Hood and Skaar, 2012).

In vitro, the absence of this most important metal affects the replication rate and growth of mycobacterial cells when plating pathological material. In addition, under aerobic conditions, iron is present in the medium in an oxidized form, $\mathrm{Fe}$ (III), forming practically insoluble iron oxide hydrates, iron carbonate, and magnetite.

To transfer iron from the medium to the cell, siderophores, organic compounds that form chelates with $\mathrm{Fe}^{3+}$ are necessary. They allow the microbial cell to absorb iron in the complexes with the siderophore and actively grow. Table 1 shows this fact. The simultaneous presence of iron and mycobacterial siderophore in the medium ensured the growth of more colonies and the accumulation of bacterial mass. In addition, vice versa, the absence of iron and siderophore in the medium (control medium V) or one component (medium IV) reduced the growth qualities of the medium at the isolation of the pathogen from pathological material.

The culture filtrate is a variety of $M$. phlei metabolic and autolysis products, including siderophores (mycobactin and exochelin), which mediate the iron absorption by mycobacteria.

It should be noted that pathogenic mycobacteria do not form exochelin peptide siderophore synthesized by non-pathogenic mycobacteria (in this case M. phlei), but utilize it. Apparently, in the culture filtrate, the substances necessary for the growth of M. bovis are found in a greater amount and in more bioavailable form than in the alcohol extract of M. phlei. The results of the study show that the presence of exochelin and other products of metabolism and autolysis of M.phlei contained in the culture filtrate, in comparison with other growth factors, contribute to the accelerated indication of $M$. bovis from biological material.

The next stage of our research was to study the growth activity of subcultures of M. bovis, strain Vallee of the first generations in the absence of siderophores in the medium. For this, from each medium, a suspension of the first generation of grown cultures was inoculated on a nutrient medium without siderophore and iron (Table 2). 
Table 2 - The intensity of growth of $M$. bovis subcultures of the first generation on a nutrient medium without iron and siderophores

\begin{tabular}{|c|c|c|c|c|c|c|c|c|}
\hline \multirow{3}{*}{ Subculture } & \multirow{3}{*}{$\begin{array}{l}\text { No. of } \\
\text { test tube }\end{array}$} & \multicolumn{6}{|c|}{ Days of cultivation } & \multirow{3}{*}{$\begin{array}{c}\text { Bacterial mass } \\
\text { weight, mg/test } \\
\text { tube, } M \pm \mathrm{m}\end{array}$} \\
\hline & & 5 & 6 & 8 & 10 & 15 & 20 & \\
\hline & & \multicolumn{6}{|c|}{ Number of colonies } & \\
\hline \multirow{5}{*}{$\begin{array}{l}\text { From medium I } \\
\qquad(\mathrm{CF}+\mathrm{Fe})\end{array}$} & 1 & - & + & ++ & ++ & +++ & ++++ & \multirow{5}{*}{$91.1 \pm 3.1$} \\
\hline & 2 & - & - & + & ++ & +++ & ++++ & \\
\hline & 3 & - & + & ++ & ++ & +++ & ++++ & \\
\hline & 4 & - & + & + & + & ++ & ++++ & \\
\hline & 5 & - & + & + & + & ++ & ++++ & \\
\hline \multirow{5}{*}{$\begin{array}{l}\text { From medium II } \\
\quad(\mathrm{ExNoc}+\mathrm{Fe})\end{array}$} & 1 & - & - & + & + & ++ & +++ & \multirow{5}{*}{$77.4 \pm 4.2$} \\
\hline & 2 & - & + & + & ++ & +++ & ++++ & \\
\hline & 3 & - & - & + & ++ & ++ & +++ & \\
\hline & 4 & - & - & + & + & + & ++ & \\
\hline & 5 & - & - & + & + & + & ++ & \\
\hline \multirow{5}{*}{$\begin{array}{l}\text { From medium III } \\
\qquad(\mathrm{ExPhl}+\mathrm{Fe})\end{array}$} & 1 & - & + & ++ & ++ & +++ & ++++ & \multirow{5}{*}{$89.8 \pm 3.1$} \\
\hline & 2 & - & - & ++ & ++ & +++ & ++++ & \\
\hline & 3 & - & - & + & + & ++ & ++++ & \\
\hline & 4 & - & + & + & ++ & ++ & ++++ & \\
\hline & 5 & - & - & + & + & ++ & ++++ & \\
\hline \multirow{5}{*}{$\begin{array}{l}\text { From medium IV } \\
\qquad(\mathrm{ExPhl})\end{array}$} & 1 & - & - & + & + & ++ & ++++ & \multirow{5}{*}{$89.3 \pm 2.7$} \\
\hline & 2 & - & + & + & + & ++ & ++++ & \\
\hline & 3 & - & + & + & ++ & +++ & ++++ & \\
\hline & 4 & - & + & ++ & + & +++ & ++++ & \\
\hline & 5 & - & - & + & + & ++ & ++++ & \\
\hline \multirow{5}{*}{$\begin{array}{l}\text { From medium } \mathrm{V} \\
\quad(\text { control })\end{array}$} & 1 & - & + & ++ & ++ & +++ & ++++ & \multirow{5}{*}{$88.8 \pm 3.8$} \\
\hline & 2 & - & + & + & ++ & +++ & ++++ & \\
\hline & 3 & - & + & ++ & ++ & +++ & ++++ & \\
\hline & 4 & - & - & + & + & ++ & ++++ & \\
\hline & 5 & - & - & + & + & ++ & ++++ & \\
\hline
\end{tabular}

Notes: (-) - no colonies; (+) - up to 10 colonies; $(++)$ - from 10 to 30 colonies; $(+++)-$ from 30 to 50 colonies; $(++++)-$ more than 50 colonies; CF - cultural filtrate M. phlei; ExNoc - ethanol extract N. asteroides; ExPhl - ethanol extract M. phlei; $\mathrm{Fe}-$ citric ammonium iron.

As a result of the cultural study, it was found that, regardless of the composition of the medium on which the culture was originally isolated, when subcultured to media without iron and siderophore, the first colonies of subcultures were observed at the same time on the $6^{\text {th }}-8^{\text {th }}$ days with a similar growth rate.

In addition, the culture grown on the control medium $\mathrm{V}$, which initially did not include siderophores and iron, showed an identical growth of colonies during subculturing and at the same time as on the other media.

Mycobacteria of tuberculosis complex regulate iron metabolism at the level of gene transcription, inducing the expression of genes for iron uptake in case of iron deficiency and activating its storage when it is readily available through the function of an iron-dependent regulator to turn off iron absorption and turn on its conservation (Rodriguez et al., 2002; Gupta et al., 2009).

The absence of growth factors and iron in the nutrient medium did not have a negative effect on the rate and intensity of subculture growth. This was due to the fact that the iron accumulated by mycobacteria through the siderophores served as a reserve for overcoming its deficiency, and the subculture that grew on the control medium (without iron and siderophore) managed to adapt.

Therefore, the absence of iron and siderophores from M. phlei in the medium also did not have a particular effect on the accumulation of bacterial mass, its amount ranged from $89.3 \pm 2.7 \mathrm{mg}$ to $91.1 \pm 3.1$; a smaller amount of bacterial mass was obtained from the subculture, originally grown on medium II (with ethanol extract of $N$. asteroides $+\mathrm{Fe}$ ).

Conclusions. Since the work was of a research nature, we studied the effect of siderophores on the rate and intensity of growth on one pathogen. However, it has provided a 'proof of concept' that siderophores found in culture filtrate or alcoholic extract of saprophytic mycobacteria can be valuable supplements in culture media for isolating tuberculosis pathogens from pathological material. 


\section{References}

Agoro, R. and Mura, C. (2019) 'Iron supplementation therapy, a friend and foe of mycobacterial infections?', Pharmaceuticals, 12(2), p. 75. doi: 10.3390/ph12020075.

Andrews, S. C., Robinson, A. K. and Rodríguez-Quiñones, F. (2003) 'Bacterial iron homeostasis', FEMS Microbiology Reviews, 27(2-3), pp. 215-237. doi: 10.1016/S0168-6445(03)00055-X.

Arnold, F. M., Weber, M. S., Gonda, I., Gallenito, M. J., Adenau, S., $\quad$ Egloff, P., Zimmermann, I., $\quad$ Hutter, C. A. J., Hürlimann, L. M., Peters, E. E., Piel, J., Meloni, G., Medalia, O. and Seeger, M. A. (2020) 'The $A B C$ exporter IrtAB imports and reduces mycobacterial siderophores', Nature, 580(7803), pp. 413-417. doi: 10.1038/s41586-020-2136-9.

Dhakal, D., Rayamajhi, V., Mishra, R. and Sohng, J. K. (2019) 'Bioactive molecules from Nocardia: diversity, bioactivities and biosynthesis', Journal of Industrial Microbiology and Biotechnology, 46(3-4), pp.385-407. doi: 10.1007/s10295-018-02120-y.

DiGiuseppe Champion, P. A. and Cox, J. S. (2007) 'Protein secretion systems in mycobacteria', Cellular Microbiology, 9(6), pp. 1376-1384. doi: 10.1111/j.1462-5822.2007.00943.x.

Dobin, V. L., Demikhov, V. G. and Zharikova, M. P. (2016) 'Iron exchange in mycobacteria' [Obmen zheleza u mikobakteriy], Tuberculosis and Lung Diseases [Tuberkulez $i$ bolezni legkikh], 94(7), pp.6-10. doi: 10.21292/2075-12302016-94-7-6-10. [in Russian].

Dobryszycka, W. (1997) 'Biological functions of haptoglobin new pieces to an old puzzle', European Journal of Clinical Chemistry and Clinical Biochemistry, 35(9), p. 647-654. PMID: 9352226.

Drakesmith, H. and Prentice, A. M. (2012) 'Hepcidin and the iron-infection axis', Science, 338(6108), pp. 768-772. doi: 10.1126/science.1224577.

Fang, Z., Sampson, S. L., Warren, R. M., Gey van Pittius, N. C. and Newton-Foot, M. (2015) 'Iron acquisition strategies in mycobacteria', Tuberculosis, 95(2), pp. 123-130. doi: 10.1016/ j.tube.2015.01.004.

Gokarn, K. and Pal, R. B. (2017) 'Preliminary evaluation of anti-tuberculosis potential of siderophores against drugresistant Mycobacterium tuberculosis by mycobacteria growth indicator tube-drug sensitivity test', BMC Complementary and Alternative Medicine, 17(1), p. 161. doi: 10.1186/s12906-0171665-8.

Gupta, V., Gupta, R. K., Khare, G., Salunke, D. M. and Tyagi, A. K. (2009) 'Crystal Structure of Bfr A from Mycobacterium tuberculosis: Incorporation of selenomethionine results in cleavage and demetallation of haem', PLoS ONE, 4(11), p. e8028. doi: 10.1371/journal.pone.0008028.

He, J. and Xie, J. (2011) 'Advances in Mycobacterium siderophore-based drug discovery', Acta Pharmaceutica Sinica B, 1(1), pp. 8-13. doi: 10.1016/j.apsb.2011.04.008.

Hood, M. I. and Skaar, E. P. (2012) 'Nutritional immunity: transition metals at the pathogen-host interface', Nature Reviews Microbiology, 10(8), pp. 525-537. doi: 10.1038/nrmicro2836.

Hoshino, Y., Chiba, K., Ishino, K., Fukai, T., Igarashi, Y., Yazawa, K., Mikami, Y. and Ishikawa, J. (2011) 'Identification of nocobactin NA biosynthetic gene clusters in Nocardia farcinica', Journal of Bacteriology, 193(2), pp. 441-448. doi: 10.1128/JB.00897-10.

Jones, C. M. and Niederweis, M. (2011) 'Mycobacterium tuberculosis can utilize heme as an iron source', Journal of Bacteriology, 193(7), pp. 1767-1770. doi: 10.1128/JB.01312-10.

Knobloch, P., Koliwer-Brandl, H., Arnold, F. M., Hanna, N., Gonda, I., Adenau, S., Personnic, N., Barisch, C., Seeger, M. A.,
Soldati, T. and Hilbi, H. (2020) 'Mycobacterium marinum produces distinct mycobactin and carboxymycobactin siderophores to promote growth in broth and phagocytes', Cellular Microbiology, 22(5), p. e13163. doi: 10.1111/cmi.13163.

Lyamin, A. V., Khaliulin, A. V., Ismatullin, D. D., Kozlov, A. V. and Baldina, O. A. (2016) 'Iron as essential growth factor mycobacteria' [Zhelezo kak essentsial'nyy faktor rosta mikobakteriy], Bulletin of the Samara Scientific Center of the Russian Academy of Sciences [Izvestiya Samarskogo nauchnogo tsentra Rossiyskoy akademii nauk], 18(5.2), p. 320-327. Available at: https://elibrary.ru/item.asp?id=28990361. [in Russian].

Männle, D., McKinnie, S. M. K., Mantri, S. S., Steinke, K., Lu, Z., Moore, B. S., Ziemert, N. and Kaysser, L. (2020) 'Comparative genomics and metabolomics in the genus Nocardia', mSystems, 5(3), p. e00125-20. doi: 10.1128/mSystem s.00125-20.

Rajiv, J., Dam, T., Kumar, S., Bose, M., Aggarwal, K. K. and Babu, C. R. (2001) 'Inhibition of the in-vitro growth of Mycobacterium tuberculosis by a phytosiderophore', Journal of Medical Microbiology, 50(10), pp. 916-918. doi: 10.1099/00221317-50-10-916.

Reddy, P. V., Puri, R. V., Chauhan, P., Kar, R., Rohilla, A., Khera, A. and Tyagi, A. K. (2013) 'Disruption of mycobactin biosynthesis leads to attenuation of Mycobacterium tuberculosis for growth and virulence', The Journal of Infectious Diseases, 208(8), pp. 1255-1265. doi: 10.1093/infdis/jit250.

Rodriguez, G. M. (2006) 'Control of iron metabolism in Mycobacterium tuberculosis', Trends in Microbiology, 14(7), pp. 320-327. doi: 10.1016/j.tim.2006.05.006.

Rodriguez, G. M. and Smith, I. (2006) 'Identification of an $\mathrm{ABC}$ transporter required for iron acquisition and virulence in Mycobacterium tuberculosis', Journal of Bacteriology, 188(2), pp. 424-430. doi: 10.1128/JB.188.2.424-430.2006.

Rodriguez, G. M., Voskuil, M. I., Gold, B., Schoolnik, G. K. and Smith, I. (2002) 'ideR, an essential gene in Mycobacterium tuberculosis: Role of ideR in iron-dependent gene expression, iron metabolism, and oxidative stress response', Infection and Immunity, 70(7), pp.3371-3381. doi: 10.1128/IAI.70.7.33713381.2002 .

Takatsuka, M., Osada-Oka, M., Satoh, E. F., Kitadokoro, K., Nishiuchi, Y., Niki, M., Inoue, M., Iwai, K., Arakawa, T., Shimoji, Y., Ogura, H., Kobayashi, K., Rambukkana, A. and Matsumoto, S. (2011) 'A histone-like protein of mycobacteria possesses ferritin superfamily protein-like activity and protects against DNA damage by fenton reaction', PLOS ONE, 6(6), p. e20985. doi: 10.1371/journal.pone.0020985.

Tanner, R., O'Shea, M. K., White, A. D., Müller, J., HarringtonKandt, R., Matsumiya, M., Dennis, M. J., Parizotto, E. A., Harris, S., Stylianou, E., Naranbhai, V., Bettencourt, P., Drakesmith, H., Sharpe, S., Fletcher, H. A. and McShane, H. (2017) 'The influence of haemoglobin and iron on in vitro mycobacterial growth inhibition assays', Scientific Reports, 7(1), p. 43478. doi: $10.1038 /$ srep43478.

Tolosano, E. and Altruda, F. (2002) 'Hemopexin: Structure, function, and regulation', DNA and Cell Biology, 21(4), pp. 297-306. doi: 10.1089/104454902753759717.

Tullius, M. V., Harmston, C. A., Owens, C. P., Chim, N., Morse, R. P., McMath, L. M., Iniguez, A., Kimmey, J. M., Sawaya, M. R., Whitelegge, J. P., Horwitz, M. A. and Goulding, C. W. (2011) 'Discovery and characterization of a unique mycobacterial heme acquisition system', Proceedings of the National Academy of Sciences, 108(12), pp. 5051-5056. doi: 10.1073/pnas.1009516108. 